Author affiliations appear at the end of this article.

Published online ahead of print at www.jco.org on January 20, 2015

Processed as a Rapid Communication manuscript.

American Society of Clinical Oncology Clinical Practice Guideline Committee approval: November 5, 2014.

Editor's note: This American Society of Clinical Oncology 2014 clinical practice guideline update reaffirms and summarizes the recommendations that were previously published in 2013; the 2013 recommendations remain current as of October 2014. Additional information, including Data and Methodology Supplements, slide sets, clinical tools and resources, and links to patient information at www.cancer.net, is available at www.asco.org/guidelines/vte.

Authors' disclosures of potential conflicts of interest are found in the article online at www.jco.org. Author contributions are found at the end of this article.

Corresponding author: American Society of Clinical Oncology, 2318 Mill Rd, Suite 800 , Alexandria, VA 22314

e-mail: guidelines@asco.org.

(c) 2015 by American Society of Clinica Oncology

0732-183X/15/3306w-654w/\$20.00

DOI: 10.1200/JCO.2014.59.7351

\title{
Venous Thromboembolism Prophylaxis and Treatment in Patients With Cancer: American Society of Clinical Oncology Clinical Practice Guideline Update 2014
}

Gary H. Lyman, Kari Bohlke, Alok A. Khorana, Nicole M. Kuderer, Agnes Y. Lee, Juan Ignacio Arcelus, Edward P. Balaban, Jeffrey M. Clarke, Christopher R. Flowers, Charles W. Francis, Leigh E. Gates, Ajay K. Kakkar, Nigel S. Key, Mark N. Levine, Howard A. Liebman, Margaret A. Tempero, Sandra L. Wong, Mark R. Somerfield, and Anna Falanga

\section{$\begin{array}{llllllll}\text { A } & \text { B } & \text { S } & \text { T } & \text { R } & \text { A } & \text { C } & \text { T }\end{array}$}

\section{Purpose}

To provide current recommendations about the prophylaxis and treatment of venous thromboembolism (VTE) in patients with cancer.

\section{Methods}

PubMed and the Cochrane Library were searched for randomized controlled trials, systematic reviews, meta-analyses, and clinical practice guidelines from November 2012 through July 2014. An update committee reviewed the identified abstracts.

\section{Results}

Of the 53 publications identified and reviewed, none prompted a change in the 2013 recommendations.

\section{Recommendations}

Most hospitalized patients with active cancer require thromboprophylaxis throughout hospitalization. Routine thromboprophylaxis is not recommended for patients with cancer in the outpatient setting. It may be considered for selected high-risk patients. Patients with multiple myeloma receiving antiangiogenesis agents with chemotherapy and/or dexamethasone should receive prophylaxis with either low-molecular weight heparin (LMWH) or low-dose aspirin. Patients undergoing major surgery should receive prophylaxis starting before surgery and continuing for at least 7 to 10 days. Extending prophylaxis up to 4 weeks should be considered in those undergoing major abdominal or pelvic surgery with high-risk features. LMWH is recommended for the initial 5 to 10 days of treatment for deep vein thrombosis and pulmonary embolism as well as for long-term secondary prophylaxis (at least 6 months). Use of novel oral anticoagulants is not currently recommended for patients with malignancy and VTE because of limited data in patients with cancer. Anticoagulation should not be used to extend survival of patients with cancer in the absence of other indications. Patients with cancer should be periodically assessed for VTE risk. Oncology professionals should educate patients about the signs and symptoms of VTE.

\section{J Clin Oncol 33:654-656. (C) 2015 by American Society of Clinical Oncology}

\section{INTRODUCTION}

The goal of this 2014 guideline update is to provide oncologists and other clinicians with current recommendations regarding the prevention and treatment of venous thromboembolism (VTE) in patients with cancer. The American Society of Clinical Oncology (ASCO) first published an evidence-based clinical practice guideline on VTE in patients with cancer in 2007, with an updated guideline published in 2013. ${ }^{1}$ The current 2014 update assesses whether the 2013 recommendations remain valid. A complete list of previous recommen- dations is available at www.asco.org/guidelines/vte and in Data Supplement 1.

\section{METHODS}

\section{Guideline Update Process}

PubMed and the Cochrane Library were searched for randomized controlled trials, systematic reviews, meta-analyses, and clinical practice guidelines for the period from November 5, 2012, through July 2014. The disease and intervention search terms were those that were used for the 2013 guideline update. An update committee (members listed in Appendix Table A1, online only), formed in accordance 


\section{THE BOTTOM LINE}

\section{Venous Thromboembolism Prophylaxis and Treatment in Patients with Cancer: American Society of Clinical Oncology Clinical Practice Guideline Update}

\section{Interventions}

- Pharmacologic anticoagulation

\section{Target Audience}

- Medical oncologists, surgical oncologists, hospitalists, oncology nurses

\section{Key Recommendations}

- Most hospitalized patients with active cancer require thromboprophylaxis throughout hospitalization. Data are inadequate to support routine thromboprophylaxis in patients admitted for minor procedures or short chemotherapy infusion.

- Routine thromboprophylaxis is not recommended for ambulatory patients with cancer. It may be considered for highly select high-risk patients.

- Patients with multiple myeloma receiving antiangiogenesis agents with chemotherapy and/or dexamethasone should receive prophylaxis with either low-molecular weight heparin (LMWH) or low-dose aspirin to prevent venous thromboembolism (VTE).

- Patients undergoing major cancer surgery should receive prophylaxis starting before surgery and continuing for at least 7 to 10 days.

- Extending postoperative prophylaxis up to 4 weeks should be considered in those undergoing major abdominal or pelvic surgery with high-risk features.

- LMWH is recommended for the initial 5 to 10 days of treatment of established deep vein thrombosis and pulmonary embolism as well as for long-term secondary prophylaxis for at least 6 months.

- Use of novel oral anticoagulants is not currently recommended for patients with malignancy and VTE.

- Anticoagulation should not be used to extend survival of patients with cancer in the absence of other indications.

- Patients with cancer should be periodically assessed for VTE risk.

- Oncology professionals should educate patients about the signs and symptoms of VTE.

\section{Methods}

- An update committee was convened to determine whether previous recommendations remain valid based on an updated review of evidence from the medical literature.

\section{Additional Information}

- This guideline is published in Journal of Clinical Oncology. Data Supplements, including evidence tables, and clinical tools and resources can be found at www.asco.org/guidelines/vte.

with the ASCO Conflict of Interest Management Procedures for Clinical Practice Guidelines, reviewed the abstracts that were identified for predefined signals that would suggest the need to change a previous recommendation. Additional information about the results of the updated literature search (Data Supplement 2) and 2014 search strategy string and results (Data Supplement 3), as well as a discussion of the ASCO signals approach to guideline updating, are available at www.asco.org/guidelines/vte and in the 2014 Data Supplement and 2014 Methodology Supplement, respectively. A QUOROM diagram of the updated search and the clinical questions are provided in Data Supplements 4 and 5 , respectively. 


\section{Guideline Disclaimer}

The clinical practice guideline and other guidance published herein are provided by ASCO to assist providers in clinical decision making. The information herein should not be relied on as being complete or accurate, nor should it be considered as inclusive of all proper treatments or methods of care or as a statement of the standard of care. With the rapid development of scientific knowledge, new evidence may emerge between the time information is developed and when it is published or read. The information is not continually updated and may not reflect the most recent evidence. The information addresses only the topics specifically identified therein and is not applicable to other interventions, diseases, or stages of diseases. This information does not mandate any particular course of medical care. Furthermore, the information is not intended to substitute for the independent professional judgment of the treating provider, because the information does not account for individual variation among patients. Recommendations reflect high, moderate, or low confidence in the net effect of a given course of action. The use of words such as "must," "must not," "should," and "should not" indicates that a course of action is recommended or not recommended for either most or many patients, but there is latitude for the treating physician to select other courses of action in individual cases. In all cases, the selected course of action should be considered by the treating provider in the context of treating the individual patient. Use of the information is voluntary. ASCO provides this information on an as-is basis and makes no warranty, express or implied, regarding the information. ASCO specifically disclaims any warranties of merchantability or fitness for a particular use or purpose. ASCO assumes no responsibility for any injury or damage to persons or property arising out of or related to any use of this information or for any errors or omissions.

This is the most recent information as of the publication date. For the most recent information, or to submit new evidence, please visit www.asco .org/guidelines/vte and the ASCO guidelines wiki at www.asco.org/ guidelineswiki.

\section{Guideline and Conflicts of Interest}

The update committee was assembled in accordance with the ASCO Conflict of Interest Management Procedures for Clinical Practice Guidelines (summarized at http://www.asco.org/rwc). Members of the committee completed the ASCO disclosure form, which requires disclosure of financial and other interests that are relevant to the subject matter of the guideline, including relationships with commercial entities that are reasonably likely to experience direct regulatory or commercial impact as a result of promulgation of the guideline. Categories for disclosure include employment relationships, consulting arrangements, stock ownership, honoraria, research funding, and expert testimony. In accordance with these procedures, the majority of the members of the committee did not disclose any such relationships.

\section{RESULTS}

The search yielded 53 publications. After careful review of the identified publications, the update committee concluded that there were no results that would change the 2013 guideline recommendations. ${ }^{1} \mathrm{~A}$ bibliography of the results of the updated literature search is provided in Data Supplement 2.

\section{RECOMMENDATIONS}

The 2014 recommendations are listed in the Bottom Line Box. These recommendations are consistent with the previous (2013) recommendations.

ASCO believes that cancer clinical trials are vital to inform medical decisions and improve cancer care and that all patients should have the opportunity to participate.

\section{ADDITIONAL RESOURCES}

More information, including Data and Methodology Supplements, slide sets, and clinical tools and resources, is available at www.asco.org/ guidelines/vte. Patient information is available at www.cancer.net. Visit www.asco.org/guidelineswiki to provide comments on the guideline or to submit new evidence.

\section{AUTHORS' DISCLOSURES OF POTENTIAL CONFLICTS} OF INTEREST

Disclosures provided by the authors are available with this article at www.jco.org.

\section{AUTHOR CONTRIBUTIONS}

Administrative support: Kari Bohlke

Manuscript writing: All authors

Final approval of manuscript: All authors

\section{REFERENCE}

1. Lyman GH, Khorana AA, Kuderer NM, et al: Venous thromboembolism prophylaxis and treat- ment in patients with cancer: American Society of Clinical Oncology clinical practice guideline update. J Clin Oncol 31:2189-2204, 2013

\section{Affiliations}

Gary H. Lyman, Fred Hutchinson Cancer Research Center; Gary H. Lyman and Nicole M. Kuderer, University of Washington, Seattle, WA; Kari Bohlke and Mark R. Somerfield, American Society of Clinical Oncology, Alexandria, VA; Alok A. Khorana, Cleveland Clinic, Cleveland, OH; Agnes Y. Lee, University of British Columbia, Vancouver, British Columbia; Mark N. Levine, McMaster University, Hamilton, Ontario, Canada; Juan Ignacio Arcelus, Hospital Universitario Virgen de las Nieves, University of Granada, Granada, Spain; Edward P. Balaban, Cancer Care Partnership, Mount Nittany Health and Penn State Hershey Cancer Institute, State College, PA; Jeffrey M. Clarke, Duke University Medical Center, Durham; Nigel S. Key, Lineberger Comprehensive Cancer Center, University of North Carolina, Chapel Hill, NC; Christopher R. Flowers, Emory University School of Medicine, Atlanta, GA; Charles W. Francis, James P. Wilmot Cancer Center and University of Rochester, Rochester, NY; Leigh E. Gates, Patient Representative, Denver, CO; Ajay K. Kakkar, Thrombosis Research Institute, London, United Kingdom; Howard A. Liebman, University of Southern California Keck School of Medicine and Norris Comprehensive Cancer Center, Los Angeles; Margaret A. Tempero, University of California San Francisco Pancreas Center, San Francisco, CA; Sandra L. Wong, University of Michigan, Ann Arbor, MI; and Anna Falanga, Hospital Papa Giovanni XXIII, Bergamo, Italy. 


\section{AUTHORS' DISCLOSURES OF POTENTIAL CONFLICTS OF INTEREST}

Venous Thromboembolism Prophylaxis and Treatment in Patients With Cancer: American Society of Clinical Oncology Clinical Practice Guideline Update 2014

The following represents disclosure information provided by authors of this manuscript. All relationships are considered compensated. Relationships are self-held unless noted. I = Immediate Family Member, Inst = My Institution. Relationships may not relate to the subject matter of this manuscript. For more information about ASCO's conflict of interest policy, please refer to www.asco.org/rwc or jco.ascopubs.org/site/ifc.

\section{Gary H. Lyman}

Research Funding: Amgen (Inst)

Travel, Accommodations, Expenses: Daiichi Sankyo (I)

\section{Kari Bohlke}

No relationship to disclose

\section{Alok A. Khorana}

Honoraria: LEO Pharma, AngioDynamics, Genentech, Daiichi Sankyo, Johnson \& Johnson, Boehringer Ingelheim

Consulting or Advisory Role: LEO Pharma, AngioDynamics, Daiichi Sankyo, Johnson \& Johnson

Research Funding: LEO Pharma

Travel, Accommodations, Expenses: Pfizer, Janssen

\section{Nicole M. Kuderer}

Consulting or Advisory Role: Daiichi Sankyo

Travel, Accommodations, Expenses: Daiichi Sankyo

\section{Agnes Y. Lee}

Honoraria: Boehringer Ingelheim, Pfizer, sanofi-aventis, Aviva

Consulting or Advisory Role: Bayer, Bristol-Myers Squibb, Pfizer, LEO Pharma, Daiichi Sankyo

Research Funding: Bristol-Myers Squibb (Inst), Bristol-Myers Squibb (Inst)

\section{Juan Ignacio Arcelus}

Honoraria: sanofi-aventis, AspenBio Pharma

Travel, Accommodations, Expenses: sanofi-aventis, AspenBio Pharma

Edward P. Balaban

Consulting or Advisory Role: Truven Health Analytics

Jeffrey M. Clarke

No relationship to disclose

\section{Christopher R. Flowers}

Consulting or Advisory Role: OptumRx, Algeta, Seattle Genetics Research Funding: Acerta (Inst), Infinity (Inst), Onyx Pharmaceuticals (Inst), Janssen Oncology (Inst), Gilead Sciences (Inst), Spectrum Pharmaceuticals (Inst), Celgene (Inst), TG Therapeutics (Inst), Genentech/Roche (Inst), Pharmacyclics (Inst)

Other Relationship: Celgene

Charles W. Francis

Consulting or Advisory Role: Eisai

Research Funding: Eisai

\section{Leigh E. Gates}

No relationship to disclose

\section{Ajay K. Kakkar}

Honoraria: Bayer, Boehringer Ingelheim, Pfizer, sanofi-aventis

Consulting or Advisory Role: Bayer Healthcare, Boehringer Ingelheim, sanofi-aventis, Novartis, Pfizer, Bristol-Myers Squibb, Eisai

Research Funding: Bayer (Inst), Boehringer Ingelheim (Inst), Eisai

(Inst)

\section{Nigel S. Key}

Honoraria: Novo Nordisk

Consulting or Advisory Role: Genentech/Roche, CSL Behring, Bayer

Schering Pharma

Research Funding: Baxter Biosciences (Inst)
Mark N. Levine

No relationship to disclose

\section{Howard A. Liebman}

Consulting or Advisory Role: Janssen

Speakers' Bureau: Alexion Pharmaceuticals (I)

Travel, Accommodations, Expenses: Alexion Pharmaceuticals (I), Janssen

Margaret A. Tempero

No relationship to disclose

Sandra L. Wong

No relationship to disclose

Mark R. Somerfield

No relationship to disclose

Anna Falanga

Travel, Accommodations, Expenses: Bristol-Myers Squibb 


\section{Appendix}

Table A1. ASCO Update Committee Members

\begin{tabular}{|c|c|}
\hline Member & Affiliation \\
\hline Anna Falanga, MD (co-chair)* & Division of Immunohematology and Transfusion Medicine, Hospital Papa Giovanni XXIII, Bergamo, Italy \\
\hline Gary H. Lyman, MD, MPH (co-chair)* & Fred Hutchinson Cancer Research Center and University of Washington, Seattle, WA \\
\hline Alok A. Khorana, MD* & Cleveland Clinic, Cleveland, $\mathrm{OH}$ \\
\hline Nicole M. Kuderer, MD* & University of Washington, Seattle, WA \\
\hline Juan Ignacio Arcelus, MD, PhD & Department of Surgery, Hospital Universitario Virgen de las Nieves, University of Granada, Granada, Spain \\
\hline Edward P. Balaban, DO (PGIN representative) & $\begin{array}{l}\text { Cancer Care Partnership, Mount Nittany Health and Penn State Hershey Cancer Institute, State College, } \\
\text { PA }\end{array}$ \\
\hline Jeffrey M. Clarke, MD & Duke University Medical Center, Durham, NC \\
\hline Christopher R. Flowers, MD, MS & Emory University School of Medicine, Atlanta, GA \\
\hline Charles W. Francis, MD & James P. Wilmot Cancer Center and Department of Medicine, University of Rochester, Rochester, NY \\
\hline Leigh E. Gates, BA, CPHQ (patient representative) & Denver, $\mathrm{CO}$ \\
\hline Ajay K. Kakkar, MD, BS, PhD & Thrombosis Research Institute, London, United Kingdom \\
\hline Nigel S. Key, MB, ChB, FRCP & $\begin{array}{l}\text { Division of Hematology/Oncology, Department of Medicine, Lineberger Comprehensive Cancer Center, } \\
\text { University of North Carolina, Chapel Hill, NC }\end{array}$ \\
\hline Agnes Y. Lee, MD, MSc, FRCPC & University of British Columbia, Vancouver, British Columbia, Canada \\
\hline Mark N. Levine, MD, MSc & Department of Oncology, McMaster University, Hamilton, Ontario, Canada \\
\hline Howard A. Liebman, MD & $\begin{array}{l}\text { University of Southern California, Keck School of Medicine, Jane Anne Nohl Division of Hematology, } \\
\text { Department of Medicine and Norris Comprehensive Cancer Center, Los Angeles, CA }\end{array}$ \\
\hline Margaret A. Tempero, MD & University of California San Francisco Pancreas Center, San Francisco, CA \\
\hline Sandra L. Wong, MD & Department of Surgery, University of Michigan, Ann Arbor, MI \\
\hline
\end{tabular}

NOTE. ASCO staff: Kari Bohlke, ScD, and Mark R. Somerfield, PhD.

Abbreviations: ASCO, American Society of Clinical Oncology; PGIN, Practice Guidelines Implementation Network.

*Steering committee member. 